\title{
APLIKASI TEKNOLOGI BUDIDAYA RAMAH LINGKUNGAN TERHADAP KUALITAS BUAH STROBERI
}

\author{
APPLICATIONS SUSTAINABLE FARMING TECHNOLOGY ON THE QUALITY OF \\ STRAWBERRIES
}

\author{
Bertje R.A. Sumayku'1), Tatik Wardiyati'2), Aminudin Afandhi²), dan Jeanny Polii-Mandang1) \\ 1)Fakultas Pertanian, Universitas Sam Ratulangi, Manado, Indonesia \\ 2)Fakultas Pertanian, Universitas Brawijaya, Malang, Indonesia \\ Koresponden: sumaykubertje@unsrat.ac.id
}

\begin{abstract}
This study aimed to compare the application of environment-friendly cultivation technology on the quality of strawberries. The experimental design using a factorial in a randomized block design (RAK), with 2 factors, namely: 1). Farmers treatment technology that chicken manure $20 \mathrm{t} /$ ha + Urine Rabbits 1: 5 liters of water; 2). Treatment T. koningii $15 \mathrm{~g} / \mathrm{kg}$ of soil in chicken manure 5 tons / ha). Data were analyzed by $\mathrm{t}$ test statistics, if different continued with test Duncun at 0.05 . Research results show that treatment of PP (T. koningii Technology) has Vitamin C is $27.1 \mathrm{mg} / 100 \mathrm{~g}$, higher than the Treatment PT (Technology Farmers) is $22.5 \mathrm{mg} / 100 \mathrm{~g}$. The vitamin C content of the variables were not significantly different between treatments, while the variable texture of the fruit, and sugar content were significantly different.

Keywords: applications agriculture environmentally-friendly, strawberry fruit quality
\end{abstract}

\begin{abstract}
ABSTRAK
Penelitian ini bertujuan untuk membandingkan aplikasi teknologi budidaya ramah lingkungan terhadap kualitas buah stroberi. Rancangan percobaan menggunakan faktorial dalam Rancangan Acak Kelompok (RAK), dengan 2 faktor perlakuan yaitu : 1). Perlakuan teknologi Petani yaitu pupuk kandang ayam 20 ton/ha + Urin Kelinci $1: 5$ liter air; 2). Perlakuan T. koningii $15 \mathrm{~g} / \mathrm{kg}$ tanah dalam pupuk kandang ayam 5ton/ha). Data dianalisis dengan statistik uji $t$, jika berbeda dilanjutkan dengan uji Duncun pada 0,05. Hasil penelitian menunjukkan bahwa Perlakuan PP (Teknologi T. koningii) memiliki kandungan Vitamin C adalah $27.1 \mathrm{mg} / 100 \mathrm{~g}$, lebih tinggi dari Perlakuan PT (Teknologi Petani) yaitu 22.5 $\mathrm{mg} / 100 \mathrm{~g}$. Variabel kandungan vitamin $\mathrm{C}$ tidak berbeda nyata antara perlakuan, sedangkan variabel tekstur buah, dan kandungan gula berbeda nyata.

Kata kunci: aplikasi budidaya ramah lingkungan, kualitas buah stroberi
\end{abstract}




\section{PENDAHULUAN}

Stroberi (Fragariax ananassa Duch) merupakan salah satu komoditi buah potensial berasal dari daerah subtropis. Tanaman ini menghendaki suhu $22-28^{\circ} \mathrm{C}$, di Indonesia ditanam pada lahan dataran tinggi $>1.000 \mathrm{~m}$ di atas permukaan laut (Ashari, 2006). Menurut Hanif dan Ashari (2012) sebaran stroberi di Indonesia berada di pulau Jawa, Sumatera, Bali dan dalam 5 tahun ini menyebar ke daerah Sulawesi serta Nusa Tenggara Timur. Budidaya stroberi telah dilakukan oleh petani di daerah Jawa dan Bali, seperti : Sukabumi, Cianjur, Cipanas, Lembang di Jawa Barat; Magelang di Jawa Tengah, di daerah Batu Malang Jawa Timur, di Bali daerah Buleleng, Pancasari, Bedugul, Baturiti, dan wilayah pengembangan baru berada di Tomohon Sulawesi Utara.

Hasil dan kualitas buah dipengaruhi oleh perlakuan teknis budidaya agronomi, yaitu mulsa, irigasi, perlindungan kimia, pemupukan, dan pengelolaan lahan seperti: rotasi tanaman dan tumpang sari, persiapan yang tepat dari waktu tanam, penanaman, atau status kesehatan tanah dan jenis bibit (Lamondia, et al., 2002; Pawlowska, et al., 2004). Penambahan mulsa organik dapat meningkatkan aktivitas enzim, tetapi juga dapat menurunkan biomassa mikroba (Niemi, et al., 2008). Sedangkan, penggunaan kascing meningkatkan aktivitas dehydrogenase dari mikroba (Arancon, et al., 2006).

Praktek pertanian ramah lingkungan/organik dibandingkan dengan pertanian konvensional telah terbukti meningkatkan kualitas tanah. Indikatornya berdasarkan ukuran tradisional pada sifat biologis, kimia, dan fisik tanah (Reganold, et al., 1993; Mader, et al., 2003).

T. koningii memiliki kemampuan sebagai decomposer (Mardhiansyah dan Widyastuti, 2007). Trichoderma sp. dapat menghasilkan beberapa enzim seperti $\beta$-1,3-glukonase, kitinase, protease, serta lipase yang memiliki kemampuan untuk mendegradasi dinding dan membran sel patogen (Tomia, 2005). Enzim tersebut dilaporkan dapat berperan sebagai elisitor dalam menginduksi ketahanan tanaman, selain itu potensi strain Trichoderma sp. dalam menstimulasi dan meng- induksi ketahanan tanaman perlu diteliti seperti halnya dengan mikroorganisme lain. Hasil penelitian Cutler, et al. (1989), T. Koningii mengandung koninginin A. Koninginin A merupakan produk alami dengan struktur yang khas dan dapat memacu pertumbuhan hipokotil tanaman.

Pupuk kandang ayam sebagai bahan organik untuk dijadikan kompos.Kompos sebagai pupuk organik berfungsi sebagai sumber bahan organik dan sumber hara yang sangat dibutuhkan tanaman. Pada umumnya bahan organik sebelum dikomposkan memiliki nisbah $\mathrm{C} / \mathrm{N}$ yang tinggi, karena itu sebaiknya dikomposkan terlebih dahulu sebelum diaplikasikan ke tanaman. Sutanto (2002), menjelaskan bahwa kompos yang telah matang mempunyai $\mathrm{C} / \mathrm{N}$ berkisar antara 10-20. Bahan organik dalam bentuk pupuk kandang mengandung $\mathrm{C} / \mathrm{N}$ antara 15-17 dapat digunakan langsung sebagai pupuk.

Hasil penelitian Mardhiansyah dan Widyastuti (2007), menunjukkan penambahan Trichoderma spp. pada proses pengomposan mampu meningkatkan kualitas kompos sebagai media tumbuh semai Tusam dan meningkatkan daya hidup semai Tusam. Dalam proses pengomposan terjadi pencampuran mikroba rizosfer antagonis dengan mikroba dalam bahan kompos itu sendiri (Bustaman, 2006). Singht et. al. (2008), menunjukkan bahwa penambahan vermikompos meningkatkan jumlah daun tanaman, luas daun, bobot kering dan juga meningkatkan jumlah buah. Di sisi lain, penambahan vermikompos sangat mengurangi gangguan fisiologis seperti albinism, buah malformasi dan terjadinya warna abu-abu dalam produksi stroberi yang merupakan potensi tinggi dalam kontrol patogen tanah dan peningkatan produktivitas tanaman. Pertumbuhan vegetatif tertinggi (jumlah daun/tanaman, luas daun, bobot basah dan kering tanaman) ditemukan dalam perlakuan konvensional, sedangkan rasio akar/kanopi tertinggi diperoleh pada perlakuan $4,5 \mathrm{~kg} / \mathrm{m} 2$ bahan organik.

Perlakuan bahan organik vs perlakuan konvensional pada parameter waktu berbunga lebih cepat dihasilkan oleh perlakuan bahan organik, sedangkan perlakuan konvensional waktu berbunga tertunda, kecepatan produksi tidak terpengaruh oleh jenis perlakuan (Zahra, et al., 2007). Hasil 
yang lain juga dikemukakan oleh Tõnutare, et al., (2009), menunjukkan bahwa stroberi yang dibudidayakan pada kondisi ramah lingkungan/pertanian organik memiliki kandungan padatan terlarut dan berat kering buah lebih tinggi, dibandingkan dengan stroberi yang tumbuh secara konvensional.

Tanaman stroberi bisa tumbuh di kedalaman tanah dangkal dan menghasilkan jumlah dan kualitas yang tinggi sesuai dengan jenis tanah, nilai gizi , kapasitas lapangan dan aerasi . Penggunaan kompos untuk budidaya stroberi menyebabkan peningkatan yang signifikan dalam produktivitas buah, kandungan air dan penurunan pupuk yang digunakan. Stroberi sering ditanam kembali di bidang tanah yang sama sebagai tanaman tunggal atau dalam siklus rotasi pendek menyebabkan kerusakan progresif tanah. Hasil ini menunjukkan bahwa residu stroberi pada dosis tinggi menghambat baik pertumbuhan akar primer dan sekunder dan mengubah dinamika akar di substrat sebagai akibat dari efek toksik (Neri, et al., 2005).

Referensi dan hasil penelitian tentang budidaya ramah lingkungan apakah benar dapat memberikan perbedaan pada kualitas buah stroberi, masih perlu pendalaman oleh penulis. Penelitian ini bertujuan untuk membandingkan aplikasi teknologi budidaya ramah lingkungan terhadap kualitas buah stroberi.

\section{METODE PENELITIAN}

Penelitian dilaksanakan pada bulan Februari sampai dengan Juli 2014. Lokasi penelitian di Desa Rurukan Kecamatan Tomohon Timur Kota Tomohon. Alat yang digunakan antara lain: timbangan analitik, oven, spektrofotometer, penetro meter, meteran, cangkul, gunting pangkas dan alat tulis menulis. Bahan yang digunakan meliputi bibit tanaman stroberi, mulsa plastik hitam perak, polibag untuk bibit, pupuk kandang ayam, Urin kelinci, Trichoderma koningii 1x107 CFU.

Percobaan lapangan disusun dalam Rancangan Acak Kelompok (RAK), dengan 2 perlakuan yaitu : 1) PT = Perlakuan teknologi Petani yaitu pupuk kandang ayam 20 ton/ha + Urin Kelinci $1: 5$ liter air; 2) PP = Perlakuan T. koningii $15 \mathrm{~g} / \mathrm{kg}$ tanah + pupuk kandang ayam 5 ton/ha yang diulang sebanyak 5 kali.

Pengujian lapang, tanah digemburkan kemudian dibuat bedengan dengan ukuran guludan lebar $0.8 \mathrm{~m}$, tinggi $0,4-0,5 \mathrm{~m}$ jarak guludan $0,3 \mathrm{~m}$. Setelah bedengan terbentuk tahap berikutnya pemberian kompos sesuai perlakuan. Tutup bedengan dengan mulsa plastik hitam perak, buat lobang tanam sesuai jarak $20 \mathrm{~cm} \times 20 \mathrm{~cm}$ bentuk segi tiga. Penamanan bibit stoberi berasal dari stolon pertama dilakukan dengan cara dibenamkan pada lobang dan ditutup dengan media tanah halus, dijaga jangan kuncup bibit tertutup tanah.

Variabel tanaman yang diamati adalah komponen kualitas buah stroberi, meliputi : Tekstur buah, menggunakan penetro meter; Kandungan Gula, dan Kandungan Vitamin C. Analisis data variabel yang diamati menggunakan : Uji t untuk mengetahui terdapat perbedaan rataan tiap variabel antar perlakuan.

Prosedur pengamatan kualitas buah dilaksanakan di Laboratorium Pasca Panen Fakultas Pertanian Universitas Sam Ratulangi, meliputi :

\section{Perubahan Tekstur Buah}

Selama pematangan buah terjadi pelunakan jaringan. Tekstur dari buah-buahan disebabkan oleh adanya pektin dalam lamela tengah dinding sel. Pelunakan jaringan disebabkan perubahan senyawa pektin. Menurut Pantastico (1989), perubahan tekstur disebabkan oleh perubahan turgor sel sehingga menyebabkan kehilangan sifat segar dan renyah buah-buahan tersebut. Analisis perubahan tekstur buah menggunakan penetrometer.

\section{Kandungan Gula}

Kandungan gula dan asam dalam buah stroberi menentukan atribut rasa dari buah tersebut. Total gula dalam stroberi terdiri dari sukrosa, glukosa, dan fruktosa (Maniken dan Soederling, 1980). Kadar gula dihitung sebagai persen sukrosa menggunakan refractometer.

\section{Kandungan Vitamin C}

Buah yang mengandung vitamin $C$ cukup tinggi adalah stroberi dan jeruk, ketersediaan vitamin $C$ dalam sumber-sumber bahan pangan 
akan dipengaruhi oleh berbagai faktor (Hui, 2006). Pengukuran kandungan vitamin $\mathrm{C}$ menggunakan metode Titrasi.

\section{HASIL DAN PEMBAHASAN}

\section{Kekerasan Buah Stroberi}

Hasil pengamatan tekstur/kekerasan buah disajikan dalam Gambar 1. Dalam Gambar 1 dapat diketahui bahwa, pada perlakuan PP (Teknologi $T$. koningii) memiliki rataan kekerasan tertinggi adalah pada sampel pengamatan ke-3 sebesar $2.20 \mathrm{~g} / \mathrm{mm} /$ 10 det, sedangkan pada perlakuan PT (Teknologi Petani) yang memiliki rata-rata Kekerasan tertinggi sebesar $1.47 \mathrm{~g} / \mathrm{mm} / 10$ det.

Perlakuan PP (Teknologi T. koningii) yang memiliki rataan kekerasan terendah adalah pada sampel pengamatan ke-1, sedangkan pada perlakuan PT(Teknologi Petani) yang memiliki rata-rata kekerasan terendah adalah pada sampel pengamatan ke-1 dan ke-2. Kekerasan tertinggi pada perlakuan PP (Teknologi $T$. koningii). Untuk mengetahui terdapat perbedaan rataan kekerasan antar perlakuan, maka dilakukan analisis perbedaan dua populasi independen dengan statistik uji $t$. Statistik uji $t$ digunakan untuk menguji apakah terdapat perbedaan rata-rata yang signifikan antara pemberian perlakuan terhadap kekerasan. Dari Uji $t$ diperoleh kesimpulan bahwa, terdapat perbedaan rataan kekerasan yang signifikan antara perlakuan PP (Teknologi T. koningii) dan PT (Teknologi Petani) pada tingkat kepercayaan $95 \%$.

\section{Kandungan Gula}

Hasil pengamatan kandungan gula buah stroberi disajikan dalam Gambar 2.

Perlakuan PP (Teknologi $T$. koningii) yang memiliki rata-rata total kandungan gula tertinggi adalah pada sampel pengamatan ke-2 dan ke-3, sedangkan pada perlakuan PT (Teknologi Petani) yang memiliki rata-rata total kandungan gula tertinggi adalah pada sampel pengamatan ke-3. Pada perlakuan PP (Teknologi $T$. koningii) yang memiliki rata-rata total kandungan gula terendah adalah pada sampel pengamatan ke-1, sama dengan perlakuan PT (Teknologi Petani) yang memiliki ratarata total kandungan gula terendah adalah pada sampel pengamatan ke-1. Komposisi gula, asam organik, dan senyawa fenol dalam buah stroberi memberikan rasa yang khas dan 360 senyawa volatile menjadi pemicu aroma buah (Gunness, et al., 2009).

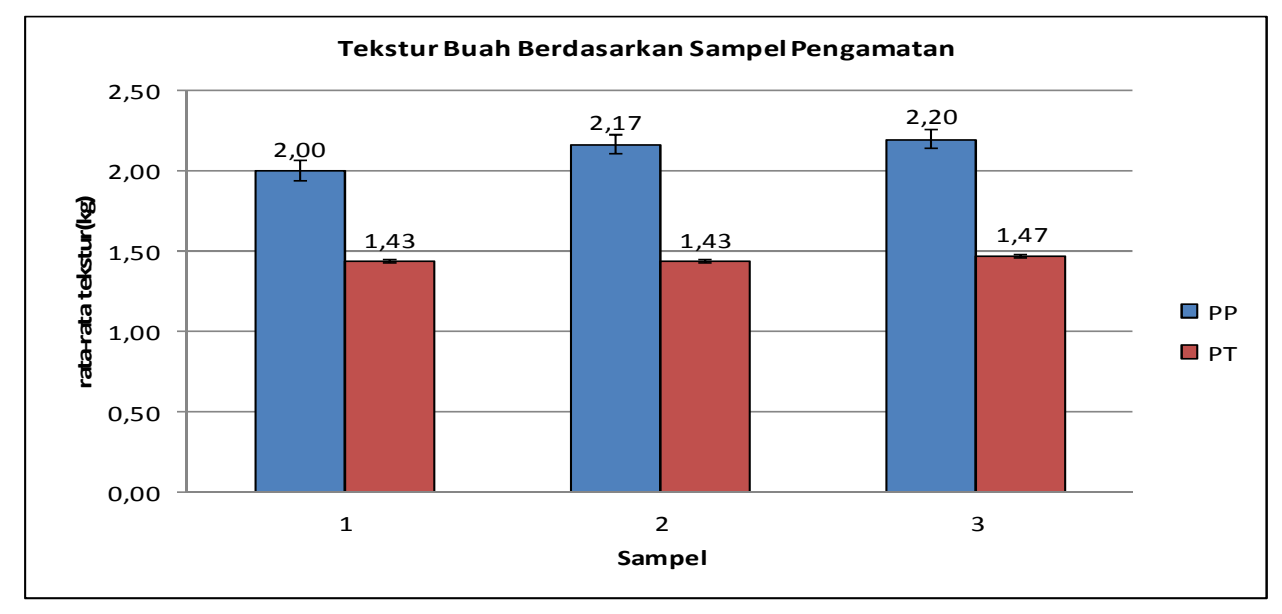

Gambar 1. Tekstur/Kekerasan Buah Stroberi $(\mathrm{g} / \mathrm{mm} / 10$ det) Tiap Pengamatan

(Figure 1. Texture / Violence strawberries $(\mathrm{g} / \mathrm{mm} / 10 \mathrm{sec}$ ) for Each Observation) 


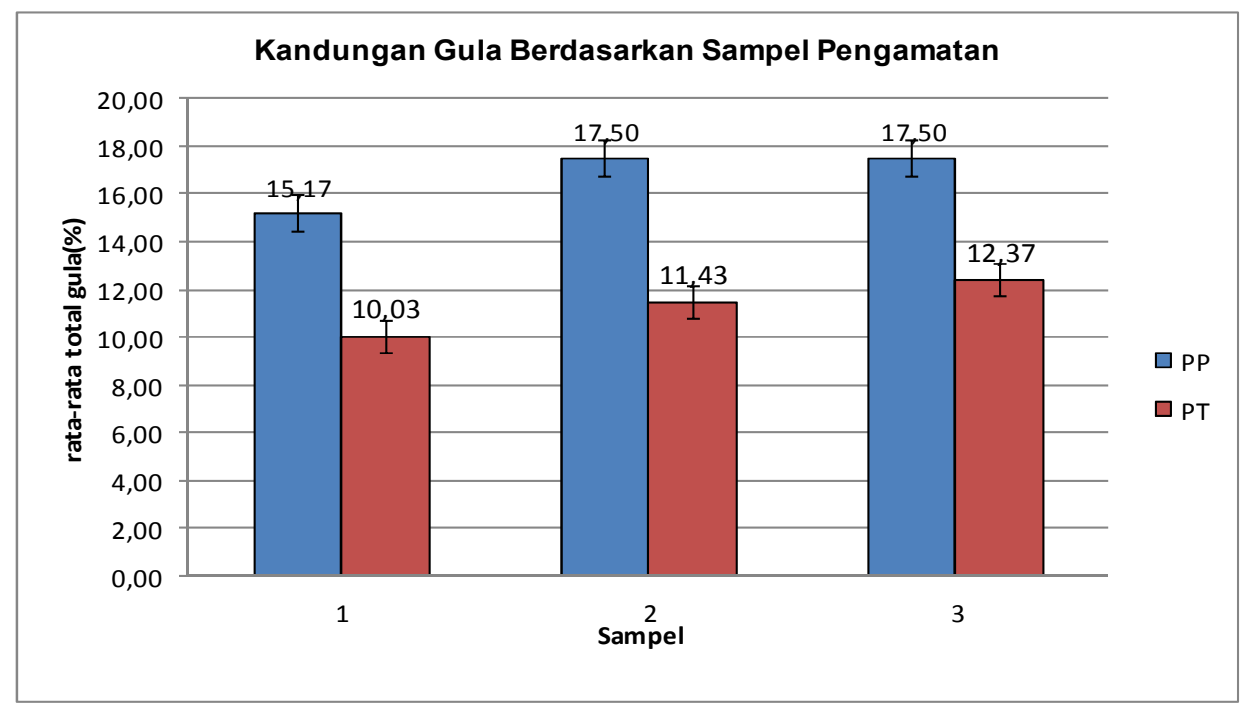

Gambar 2. Rata-rata Total Kandungan Gula Berdasarkan Sampel Pengamatan pada setiap Perlakuan (Figure 2. Average Total Ingredients Sugar Based on Observations in Each Treatment Samples)

Tabel 1. Total Kandungan Gula (\%) Buah Stroberi

(Table 1. Total Sugar Content (\%) Strawberries)

\begin{tabular}{cc}
\hline Perlakuan & Total Kandungan Gula (\%) \\
\hline PP = Teknologi $T$. koningii & $16.7+1.5$ \\
PT = Teknologi Petani & $11.2+2.5$ \\
\hline
\end{tabular}

Tabel 2. Kandungan Vitamin C mg/100g Buah Stroberi

(Table 2. Contentof Vitamin C mg / $100 \mathrm{~g}$ Strawberries)

\begin{tabular}{cc}
\hline Perlakuan & Kandungan Vitamin C mg/100g \\
\hline PP = Teknologi T. koningii & $27.1+6.3$ \\
PT = Teknologi Petani & $22.5+2.4$ \\
\hline
\end{tabular}

Data pada Tabel 1 dapat dilihat bahwa rataan total kandungan gula tertinggi pada perlakuan PP sebesar $16.7 \%$, sedangkan total kandungan gula terendah pada perlakuan PT sebesar $11.2 \%$. Untuk mengetahui terdapat perbedaan rataan total kandungan gula antar perlakuan maka dilakukan analisis perbedaan dua populasi independen dengan statistik uji $t$. Hasil Statistik uji $t$ menunjukkan terdapat perbedaan rata-rata yang signifikan antara pemberian perlakuan terhadap total kandungan gula. Dari Uji $t$ diperoleh kesimpulan bahwa terdapat perbedaan rataan total kandungan gula antar perlakuan (PP dan PT) signifikan pada tingkat kepercayaan $95 \%$.

\section{Kandungan Vitamin C}

Hasil pengamatan kandungan Vitamin C buah stroberi disajikan dalam Gambar 3.

Gambar 3 dapat diketahui bahwa pada perlakuan PP yang memiliki rata-rata kandungan Vitamin $C$ tertinggi adalah pada sampel pengamatan ke-3, sedangkan pada perlakuan PT yang memiliki rata-rata kandungan Vitamin $\mathrm{C}$ tertinggi adalah pada sampel pengamatan ke-3. Pada perlakuan PP yang memiliki rata-rata kandungan Vitamin $\mathrm{C}$ terendah adalah pada sampel pengamatan ke-2, sedangkan pada perlakuan PT yang memiliki ratarata kandungan Vitamin $C$ terendah adalah pada sampel pengamatan ke-2. 


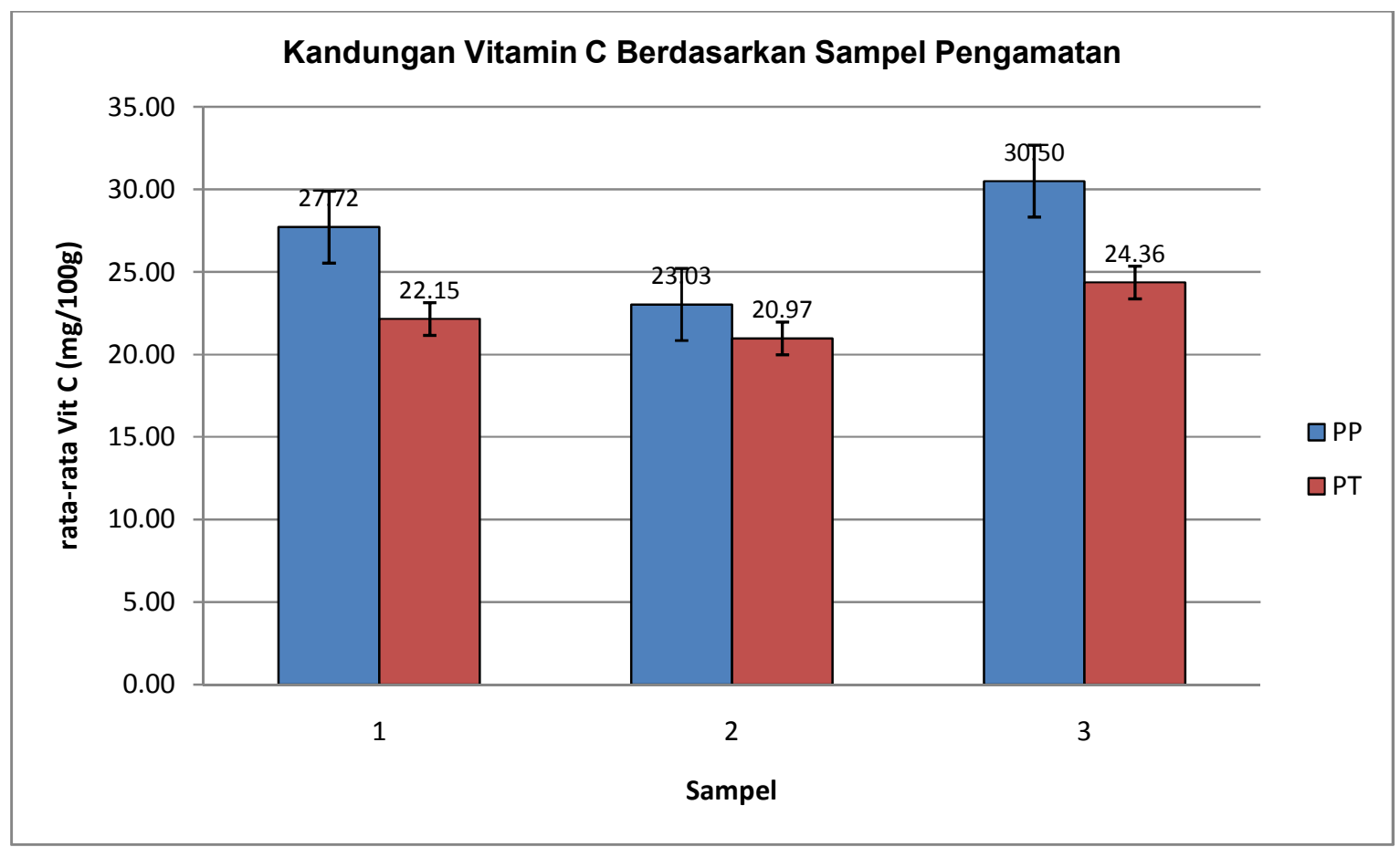

Gambar 3. Rata-rata Kandungan Vitamin C Berdasarkan Sampel Pengamatan pada setiap Perlakuan

(Figure 3. Average Vitamin C Based on Observations in Each Treatment Samples)

Data pada tabel 2 dapat diketahui bahwa, perlakuan PP (Teknologi $T$. koningii) memiliki kandungan Vitamin C adalah $27.1 \mathrm{mg} / 100 \mathrm{~g}$, lebih tinggi dari perlakuan PT (Teknologi Petani) yaitu $22.5 \mathrm{mg} / 100 \mathrm{~g}$. Rataan kandungan Vitamin $\mathrm{C}$ tertinggi pada perlakuan PP (Teknologi T. Koningii). Untuk mengetahui terdapat perbedaan rataan kandungan Vitamin $\mathrm{C}$ antar perlakuan, maka dilakukan analisis perbedaan dua populasi independen dengan statistic uji $t$. Statistik uji t digunakan untuk menguji apakah terdapat perbedaan rata-rata yang signifikan antara pemberian perlakuan terhadap kandungan Vitamin C.

Hasil Uji $t$ diperoleh kesimpulan bahwa, tidak terdapat perbedaan rataan kandungan Vitamin $\mathrm{C}$ antar perlakuan (PP $=$ Teknologi $T$. koningii) dan PT = Teknologi Petani) yang signifikan pada tingkat kepercayaan $95 \%$. Hakala et al., (2003) melaporkan bahwa budidaya organik tidak berpengaruh pada kandungan vitamin C pada varietas Polka, Honeoye dan Jonsok. Dalam percobaan sebelumnya, pada stroberi yang dibudidayakan dengan mulsa plastik dan jerami, juga ditemukan bahwa pengaruh praktik budidaya pada kandungan vitamin $C$ yang berbeda dalam tahun yang berbeda (Moor et al., 2005). Hasil tersebut menunjukkan bahwa, kandungan asam askorbat tidak mudah dipengaruhi oleh praktek budidaya.

\section{KESIMPULAN}

Terdapat perbedaan antara teknologi budidaya ramah lingkungan yang digunakan petani dengan aplikasi teknologi Trichoderma koningii terhadap kualitas buah Stroberi.

Teknologi budidaya T. koningii (PP) lebih baik dibanding teknologi Petani (PT) yang ditunjukan oleh variabel Tekstur/ kekerasan buah 2.20 $\mathrm{g} / \mathrm{mm} / 10$ det, total kandungan gula sebesar 16.72\%, dan kandungan Vitamin $\mathrm{C}$ adalah 27.1 $\mathrm{mg} / 100 \mathrm{~g}$.

\section{DAFTAR PUSTAKA}

Arancon N.Q., C.A. Edwards, and P. Bierman. 2006. Infl ences of vermicomposts on field strawberries: Part 2. Effects on soil microbiological and chemical properties. Bioresoltrce Technol. 97:831-840. 
Ashari, S. 2006. Hortikultura. Aspek Budidaya. Edisi revisi. UI-Press Jakarta. p. 410.

Bustaman, H. 2006. Seleksi Mikroba Rizosfer Antagonis Terhadap Bakteri Ralstonia solanacearum Penyebab Penyakit Layu Bakteri pada Tanaman Jahe di Lahan Tertindas. Jurnal IImu-ilmu Pertanian Indonesia. Vol. 8, No. 1: 12-18

Cutler, H.G., D.S. Himmelsbach and R.F. Arrendale. 1989. Koninginin A: A Novel Plant Growth Regulator from Trichoderma koningii. Agric. Biol. Chem., 53 (10), 26052611, 1989.

Gunness, P., O. Kravchuke, S. M. Nottingham, B.R. D'Arcy, and M. J. Gidleya, 2009. Sensory analysis of individual strawberry fruit and comparison with instrumental analysis. Journal Postharvest Biology and Technology , 52:164-172.

Hakala, M., A. Lapveteläinen, R. Huopalahti, H. Kallio, and R.Tahvonen. 2003. Effect of varieties and cultivation conditions on the composition of strawberries. Journal of Food Composition and Analysis 16, 67-80.

Hanif, Z. dan H. Ashari, 2012. Sebaran Stroberi (Fragaria $x$ ananassa) di Indonesia.Balai Penelitian Tanaman Jeruk dan Buah Sub tropika Indonesia. http://zainurihanif.com/ 2012/07/15/sebaran-stroberi-fragariaananassa-di-indonesia/ Diakses 27 Sepember 2012.

Hui, Y.H. 2006. Handbook of fruits and fruit processing. Blackwell Publising.
Lamondia, J. A., W. H. Elmer, T. L. Mervosh, and R.S. Cowles. 2002. Integrated management' of strawberry pests by rotation and intercropping. Crop Protec. 21: 837-846.

Mader, P., A. Fleissbach, D. Dubois, L. Gunst, P. Fried. 2002. Soil fertility and biodiversity in organic farming. Science 296: 1694-1697.

Maniken, K. K, and E. Soderling. 1980. A quantitative study of mamritol, sorbitol, xylitol and xylose in wild berries and commercial fruits. J. Food Sci., 45: 367371.

Mardhiansyah, M. dan S.M. Widyastuti. 2007. Potensi Trchoderma spp. pada Pengomposan Sampah Organik Sebagai Media Tumbuh dalam Mendukung Daya Hidup Semai Tusam (Pinus merkusii, etde Vries). Sagu, Vol. 6 No. 1 : 29-33.

Moor, U., K. Karp, P. Põldma and A. Pae. 2005. Cultural systems affect content of anthocyanins and vitamin $C$ in strawberry fruits. European Journal of Horticultural Sci. 70(4):195-201.

Neri, D., N. Sugiyama and A. Inujima. 2005. Effects of Organic Residues on Strawberry Root Growth. International Journal of Fruit Science, Volume 5, Issue 1, pages 127137.

Niemi, R. M., M. Vepsàlàinen, K. Wallenius, K. Erkomaa, S. Kukkonen, A. Palojàrvic, nd M. Vestbergb. 2008. Conventional versus organic cropping and peat amendment: impacts on soil microbiota and their activities. Eur. J. Soil Biol 44: 419-428. 
Pantastico. 1989. Fisiologi pascapanen: Penanganan dan Pemanfaatan Buahbuahan dan sayuran Tropika dan Subtropika (terjemahan) Karmayani. Gadjah Mada University Press.

Pawlowska D., E. Zmuda, and J. Wieniarska. 2004. WPly przedplonu na plonowanie truskawki (Fragaria $x$ ananassa Duch.) Acta Sci. Pol., Hortorum C Ultu S 3 (2): 197 -206.

Reganold JP, Palmer AS, Lockhart JC, Macgregor AN.,1993. Soil quality and financial performance of biodynamic and conventional farms in New Zealand. Science 260: 344-349.

Singh R., R.R. Sharma., S. Kumar., R.K. Gupta., and R.T. Patil. 2008. Vermicompost substitution influences growth, physiological disorders, fruit field and quality of strawberry (Fragaria $x$ ananassa Duch.). Bioresource Tech. 99: 8507-851
Sutanto, R., 2002. Penerapan Pertanian Organik; Pemasyarakatan dan Pengembangan. Kanisius, Yogyakarta.

Tomia, A., 2005. Identifikasi penyakit utama pada daun Acacia crassicarpa Cunn ex Benth dan alternatif pengendaliannya dengan menggunakan Trichoderma sp. Tesis. Bogor: IPB.

Tõnutare, T., U. Moor., K. Mölder and P. Põldma. 2009. Fruit composition of organically and conventionally cultivated strawberry 'Polka. Agronomy Research 7 (Special issue II), 755-760.

Zahra, A.T.R., K. Al-Ismail and F. Shata. 2007. Effect Of organic and Conventional system on fruit Quality of Strawberry (Fragaria $x$ ananassa Duch) ground under Plastic House Conditionsin Jordan Valley. Acta Hortic.741 : 159-172 